\title{
Interculturalidade e inclusão: o contributo das práticas de leitura na Educação Pré-Escolar
}

\section{Interculturality and inclusion: the contribution of reading practices to Early Childhood Education}

\author{
Dulce Melão \\ Instituto Politécnico de Viseu
}

\begin{abstract}
Resumo
Neste estudo procuramos compreender o contributo das práticas de leitura no jardim de infância para a edificação de trajetórias literácitas propiciadoras da promoção da interculturalidade e da inclusão, face aos objetivos traçados no âmbito do domínio da Linguagem Oral e Abordagem à Escrita (conciliando-o transversalmente com a área de Formação Pessoal e Social). A nossa análise incide em dois livros: Dançar nas nuvens, de Vanina Starkoff e Como Tu, de Ana Luísa Amaral, contemplando: i) os elementos paratextuais; ii) os temas; iii) o papel do/a educador/a na sua mediação. Destaca-se a importância de práticas de leitura precoce.

Palavras-chave: Interculturalidade, literacia emergente, livro, leitura, Educação Pré-Escolar.
\end{abstract}

\begin{abstract}
In this study, we sought to understand the contribution of reading practices in kindergarten to the construction of literacy paths, encouraging the promotion of interculturality and inclusion, in view of the objectives set in the field of Oral Language and Approach to Writing (reconciling it transversally with the area of Personal and Social Training). Our analysis focuses on two books: Dançar nas nuvens, by Vanina Starkoff and Como Tu, by Ana Luísa Amaral, contemplating: i) the paratextual elements; ii) the themes; iii) the role of the educator in their mediation. The analysis performed highlights the importance of early reading practices.

Keywords: Interculturality, emergent literacy, book, reading, Early Childhood Education.
\end{abstract}

\section{Enquadramento teórico}

Lavanchy, Gajardo e Dervin (2011) chamam a atenção para o facto de a palavra «intercultural» se ter disseminado amplamente na sociedade, surgindo ancorada no vocabulário de diferentes disciplinas e áreas de investigação e exibindo uma flutuação de sentidos e de níveis de interpretação nem sempre consensuais. Não sendo nosso objetivo refletir, de forma aprofundada, sobre os limites, tensões e contradições suscitados pelo termo, interessa-nos o facto de tal debate ter propiciado o florescimento de outros termos, como interculturalidade e multiculturalismo, merecendo cuidado acrescido. Nesse sentido, no que respeita à arena educativa, importa ter em consideração a preferência pelo primeiro, interculturalidade, sendo reconhecido: i) o seu caráter dinâmico, contemplando relações em evolução geradas através da interação entre diferentes culturas (UNESCO, 2006); ii) a partilha e a cooperação que lhe estão implícitas, fundadas no respeito e na empatia pelo Outro (Santos, Araújo e Sá \& Simões, 2012); iii) a ênfase colocada na relevância da(s) descoberta(s) da diversidade e (re)interpretação de outras culturas (Layne \& Dervin, 2016). Como frisado por Cardona, Nogueira, Vieira, Uva e Tavares (2015, p. 41), «a prática da interculturalidade é algo que urge assumir por todas as pessoas com responsabilidades educativas e formativas das gerações mais jovens, já que a inevitabilidade da vivência com a diversidade é clara». Há, no entanto, múltiplos desafios a considerar.

Estudos realizados contemplando práticas interculturais em contexto educativo apontam para: i) a existência de representações plurais e diversificadas, por parte dos profissionais da Educação, sobre o significado de tais práticas, bem como para a necessidade de realizar projetos educativos que as clarifiquem e as promovam (Santos, Araújo e Sá \& Simões, 2012); ii) a sua importância no jardim de infância, sempre consolidadas numa formação que as possibilite apoiar, acompanhar e (re)construir (Layne \& Dervin, 2016); iii) a relevância do conhecimento e da seleção, por parte do/ educador/a, de materiais didáticos de qualidade, nomeadamente no que respeita à literatura para a infância, rejeitando possíveis estereótipos pré-existentes (Marques \& Borges, 2012).

É igualmente reconhecido que, ao partilhar com as crianças as suas estratégias de leitura, o/a educador/a, pode facilitar a (re)construção de itinerários de compreensão de diferentes culturas e de respeito pelas mesmas, promovendo a educação intercultural e contribuindo para o desenvolvimento da literacia emergente, alicerçada no prazer e motivação para ler e para escrever (Muñoz \& Anwandter, 2011; Silva, Marques, Mata \& Rosa, 2016).

$\mathrm{Na}$ recente European Declaration on the Right to Literacy (Valtin et al., 2016) são destacados, entre outros, aspetos relacionados com o desenvolvimento da literacia emergente, sublinhando-se a necessidade de: i) ler com 
regularidade às crianças, de modo a aumentar o seu interesse e a sua motivação para a leitura; ii) criar um ambiente literácito rico, propiciando oportunidades de leitura de «histórias», de álbuns e de rimas; iii) envolver as crianças em atividades que lhes proporcionem o contacto com materiais impressos, possibilitando-lhes compreender a natureza da leitura e da escrita.

Outros estudos, a nível nacional e internacional, têm também colocado o foco de atenção na relevância da literacia emergente na educação pré-escolar (por exemplo, Saracho, 2017; Cruz et al., 2014), apontando para o contributo do desenvolvimento de atividades de «leitura precoce» no que respeita ao robustecimento da compreensão das características da linguagem impressa (Muñoz \& Anwandter, 2011; Villalón \& Viviani, 2009).

Nas Orientações curriculares para a Educação PréEscolar (Silva et al., 2016) é vincada igualmente a importância de «(...) facilitar a emergência da linguagem escrita, através do contacto e uso da leitura e da escrita em situações reais e funcionais associadas ao quotidiano da criança» (Silva et al., 2016, p. 6).

No que se refere à motivação para a leitura, o livro assume particular relevo, sendo encarado neste documento orientador como «instrumento» fundamental do contacto com a escrita e propiciando a (re)descoberta do prazer da leitura, aliada ao desenvolvimento da sensibilidade estética. Importa, também, frisar o papel fundamental do/a educador/a enquanto mediador/a da promoção da leitura e da escrita, aspeto crescentemente destacado na literatura de especialidade (por exemplo, Noreña \& Daza, 2013; Tabernero, 2013), de forma a que estas sejam valorizadas pelas crianças.

\section{Objetivos do estudo e método}

Face ao exposto no ponto anterior, neste estudo norteia-nos o objetivo de compreender o contributo das práticas de leitura no jardim de infância para a edificação de tais trajetórias literácitas no âmbito da educação intercultural, possibilitando o cumprimento dos objetivos traçados no âmbito do domínio da Linguagem Oral e Abordagem à Escrita (conciliando-o transversalmente com a área de Formação Pessoal e Social).

A nossa análise incide em dois livros, de cariz distinto, indicados no âmbito do Plano Nacional de Leitura: Dançar nas nuvens, de Vanina Starkoff (recomendado para a Educação Pré-Escolar, destinado a leitura a voz alta) e Como Tu, de Ana Luísa Amaral (recomendado para apoio a projetos relacionados com a cidadania, na Educação Pré-Escolar, 1. ${ }^{\circ}$ e $2 .^{\circ}$ anos de escolaridade).

A seleção destes dois livros foi realizada tendo em consideração: i) a riqueza da sua paratextualidade; ii) a relação intrínseca estabelecida entre texto e ilustração; iii) o modo como promovem e alimentam a imaginação dos leitores; iv) o papel que podem desempenhar no que respeita à motivação para a leitura na Educação PréEscolar.

No que à metodologia diz respeito, foram contemplados os seguintes aspetos: i) os elementos paratextuais das obras e o seu contributo para a compreensão da diversidade cultural e das diferenças, bem como a sua importância para a descoberta do prazer da leitura, no âmbito do desenvolvimento da literacia emergente; ii) a temática dos livros enquanto elemento propiciador do entrelaçar do desenvolvimento da literacia emergente com a educação intercultural; iii) o papel do/a educador/a no que se refere ao processo de apropriação das convenções do código escrito por parte das crianças, em diálogo com as ilustrações dos livros.

\section{Resultados e discussão}

Nesta seção centraremos a nossa atenção na articulação dos aspetos referidos na seção anterior, apontando para a sua singularidade e transversalidade. Nesse sentido, é facultado destaque a cada um deles, sendo privilegiada, também, a sua interação e o seu cruzamento.

No âmbito do contacto precoce da criança com o livro, mormente o livro-álbum, que se distingue, de forma ousada, pela «interação perfeita» entre a palavra e a imagem (Gómez, 2013), a exploração dos elementos paratextuais tem vindo a ser consensualmente reconhecida enquanto facilitadora de práticas de literacia emergente que favorecem o prazer da leitura (Leal, Gamelas, Peixoto \& Cadima, 2014; Sebástian, 2016).

Nos dois livros selecionados, de escopo, tipología e temáticas diferentes, a atenção concedida aos elementos paratextuais (por exemplo, a capa, a contracapa, as guardas e a página de rosto) favorece uma exploração particularmente rica que possibilita amplificar a etapa da pré-leitura com as crianças, «(...) permitindo, desde um primeiro contacto, a formulação de expectativas com vista à realização de inferências essenciais ao processo de compreensão» (Ramos, 2011, p. 32).

Em Dançar nas nuvens (Starkoff, 2010) capa e contracapa retratam um amplo espaço eivado de cores invulgares, no qual se destaca uma menina cujo sonho é, simplesmente, dançar nas nuvens. Para além da paleta cromática apelativa, elementos como o conjunto de casas retratadas, de aspeto e de dimensões inusitadas, em contraste com a menina sentada no cimo do «telhado», suscitam, de imediato a curiosidade dos leitores. A união da capa e da contracapa propicia, também, fazer previsões sobre o espaço no qual se desenrolará a ação e sobre a sua relevância.

Nas guardas iniciais e finais do livro repousam nuvens que envolvem os leitores, desafiados por um papagaio de papel que se adivinha companheiro de (futuras) brincadeiras. A página de rosto, ao repetir alguns dos elementos da capa (como as casas, por exemplo), omitindo outros, convida a chamar a atenção das crianças para a importância do detalhe, suscitando curiosidade acrescida e incrementado as possibilidades de questionamento sobre a história narrada.

Como sublinha Gómez (2013, p. 123), «Leer libros álbumes exige a mediadores y lectores dejarse llevar por una aventura que no arriba a respuestas acabadas, a una sola interpretación, a conclusiones y desenlaces, sino más bien a nuevas preguntas, a nuevas miradas que nos interpelan».

Criada a partir do texto do espetáculo Amor aos pedaços, apresentado em 2011 no Teatro do Campo Alegre (Porto), Como Tu (Amaral, 2012a) exibe, a partir da capa, com belíssimas ilustrações de Elsa Navarro, a 
união da(s) diferença(s) e o respeito pela singularidade, ilustrados através das personagens apresentadas: meninos e meninas acompanhados de uma lontra e de um peixe à espreita (aos quais se juntarão um gato sorridente na contracapa, bem como um sapo, a exigir particular atenção ao pormenor), aguçando a curiosidade dos leitores.

À elegância e ao cuidado plasmados neste texto poético, alia-se, pois, desde o primeiro contacto com o livro, um investimento primoroso na caracterização das personagens, com particular ênfase nas expressões faciais e no olhar, como frisa Ramos (2012), geradores de grande cumplicidade, logo a partir da capa.

$\mathrm{Na}$ contracapa, importa ainda salientar o destaque conferido ao texto que pretende sintetizar a riqueza da obra: «Tocando áreas que vão desde a educação sexual até à educação cívica e ambiental, este é um livro com poemas e música que falam do amor e das diferenças, da infância e do crescimento, dos sentires, das transformações e da alegria, da responsabilidade e do respeito, da vida comum a todos os seres vivos, dos espaços que vamos aprendendo a habitar. Porque cuidar quer dizer proteger, guardar, unir. E porque há tanto de gente como há tanto de mundo -».

Os aspetos destacados na contracapa fazem eco das palavras da autora do livro, que entendemos como relevantes no âmbito de uma reflexão sobre possíveis itinerários de leitura a explorar. Em entrevista a Teresa Sampaio, Ana Luísa Amaral sublinha que «Se há uma palavra fundamental aqui no livro é a palavra cuidado» (Amaral, 2012b), frisando a importância de, em seu entender, se tratar de um «livro sobre a vida», destinado, igualmente, ao público em geral.

Os elementos paratextuais destacados configuram-se como adjuvantes na motivação para a leitura, mormente numa fase precoce na qual o contacto com o livro é fundamental, facilitando a «apropriação gradual das especificidades inerentes às convenções do código escrito» (Silva et al., 2016, p. 73).

A compreensão da diversidade cultural e das diferenças é também favorecida pela temática dos dois livros em análise, alicerçada na interação versátil entre as sequências verbais e as ilustrações, desdobrando-se num manto plurissignificativo que convida à multiplicação de reencantamentos.

Em Dançar nas nuvens (Starkoff, 2010), tal diálogo entre o texto e a ilustração é muito bem conseguido, nomeadamente pelo recurso ao uso reiterado da página dupla que auxilia o/a educador/a a partilhar itinerários prazerosos na fase da leitura, possibilitando, por exemplo: i) a amplificação dos espaços retratados, favorecendo a atenção ao pormenor na celebração da diversidade de culturas, mormente através do crescimento da aldeia da menina e da descrição rica dos seus novos habitantes; ii) a elaboração de previsões sobre o desenrolar da narrativa, sobretudo no que respeita à possível concretização do sonho por parte da menina.

As cores vibrantes das ilustrações, privilegiadas ao longo da obra, captam, de imediato, a atenção, possibilitando uma caracterização apelativa do espaço e das personagens, despertando a curiosidade dos leitores e permitindo-lhes aceder a diferentes realidades culturais, de modo a que possam desenvolver «(..) atitudes de respeito e de compreensão face à diversidade» (Silva et al., 2016, p. 92). Importa frisar que nas Orientações Curriculares para a Educação Pré-Escolar a «diversidade» é entendida de forma abrangente, englobando «Diferenças culturais, sociais, étnicas, religiosas, linguísticas, de género, cognitivas, motoras ou sensoriais que, ao serem acolhidas e respeitadas no grupo, enriquecem as experiências e oportunidades de aprendizagem de cada uma e de todas as crianças» (Silva et al., 2016, p. 108).

Como sublinham Cardona et al. $(2015$, p. 36), «(...) para o desenvolvimento de um sentido de cidadania inclusivo, é necessário que cada cidadão ou cidadã desenvolva sentimentos de simpatia, empatia e solidariedade face aos outros e a outras culturas em particular». Através da exploração do livro Como $T u$ (Amaral, 2012a) a relevância de tais sentimentos pode também ser destacada, no âmbito da leitura partilhada, com ênfase no que Lapeña Gallego (2013) designa de «dimensão criativo-narrativa das ilustrações», em associação com as sequências verbais. A leitura em voz alta pode contribuir para o descortinar de tal associação, sendo o itinerário iniciado na etapa da pré-leitura e cabendo ao/à educador/educadora contribuir para lhe dar continuidade, destacando-se, por exemplo: i) o facto de os animais serem alvo de personificação, sendo-lhes concedido protagonismo desde a capa, o que contribui para alicerçar a importância das diferenças e da singularidade de cada um, numa sã convivência em comum, entretecida no «sentir»: «Pois neste mundo todo/é o sentir/que junta o cão, a lontra, o caracol,/e também o menino e a menina,/e o pai, e a mãe, a tia, o tio, a avó,/amiga ou o amigo, e o albatroz também, e os pinguins» (Amaral, 2012a, p. 59); ii) o caráter intrínseco e complementar entre texto e ilustração, de forma a reiterar a relevância do cuidar, numa bonita aliança com a empatia, bem presente, por exemplo, através da combinação do contraste entre a escuridão e a luz, nomeadamente no que respeita à caracterização de uma das personagens, a Joaninha, alvo de troça dos colegas, sendo a escolha da página dupla, numa paleta cromática onde o preto predomina, essencial à compreensão da mensagem a veicular, pelo modo como a amplia e enfatiza: «Nós às vezes/não queremos excluir,/mas por vergonha, ou medo,/ou não saber,/é isso que se faz (...) Ser excluído/ faz-nos sentir sozinhos,/diferentes de diferente!» (Amaral, 2012a, p. 45).

Mendes e Velosa (2016, p. 121) destacam que «quanto mais polissémicas forem as ilustrações, maiores possibilidades terá a criança de libertar a sua imaginação e ir construindo mundos alternativos, penetrando na estrutura simbólica e imagética com um olhar cada vez mais pormenorizado e focalizado». Sotto Mayor (2016) frisa ainda o facto de as crianças serem mais orientadas para a «visualidade», podendo as ilustrações favorecer uma multiplicidade de percursos de leitura por sua sugestão e facultar pistas sobre a continuidade da história.

No que diz respeito a Como Tu (Amaral, 2012a), tais percursos ganham, também, dimensões prazerosas pelo facto de, como frisa Ramos (2012), a ilustradora mesclar 
os tecidos, a costura e o bordado com o desenho, o que contribui para: i) acentuar a proximidade física das personagens, criando cumplicidades inesperadas com os leitores e corroborando a importância do cuidar; ii) favorecer a atenção ao pormenor, possibilitando a realização de inferências que contribuem para a compreensão na leitura.

O CD áudio que acompanha o livro é uma mais valia no que diz respeito às práticas de leitura partilhada com as crianças pois permite, no entender da autora, sublinhar «(...) aquilo que nos liga uns aos outros» (Amaral, 2012c), aliando a poesia à música e contribuindo para reforçar a ideia «de congregação, de solidariedade» (Amaral, 2012b), sendo ainda a poesia entendida nas Orientações Curriculares para a Educação Pré-Escolar como um importante «(...) meio de descoberta e de tomada de consciência da língua, para além de outros contributos, como por exemplo, a sensibilização estética» (Silva et al., 2016, p. 67).

Pelo exposto nesta seção, entendemos também que as propostas de trabalho sugeridas vão ao encontro das aprendizagens a promover no âmbito da Área de Formação Pessoal e Social, mormente no que se refere ao desenvolvimento do «respeito pelo outro e pelas suas opiniões, numa atitude de partilha e de responsabilidade social» (Silva et al., 2016, p. 44), bem como relativamente ao respeito pela diversidade e solidariedade em relação ao mundo que nos rodeia.

Encontram, ainda, eco, no Referencial de Educação para o Desenvolvimento (Torres et al., 2016), no que diz respeito ao subtema «Diversidade cultural e visões do mundo», cujos objetivos são «Valorizar a diversidade de culturas, sociedades e mundivisões, atribuindo-lhes uma relevância equitativa» (Torres et al., 2016, p. 15).

\section{Considerações finais}

O estudo realizado possibilitou-nos inferir que os elementos paratextuais dos livros em apreço, pela sua riqueza e pelas suas características inusitadas, podem contribuir para a motivação para a leitura, facultando às crianças formas plurais de olhar mundos.

Compreendemos igualmente que a temática das obras analisadas, ao conjugar a relevância do convívio da singularidade com a diversidade cultural e o respeito pelo Outro, é um elemento importante a considerar no que se refere à educação intercultural, entretecendo-se no desenvolvimento da literacia emergente.

O/a educador/a pode desempenhar um papel fundamental enquanto mediador/a de práticas educativas que favoreçam tal desenvolvimento, devendo integrar no quotidiano das crianças livros que propiciem um diálogo prazeroso entre a linguagem escrita e as ilustrações, iluminando a(s) leitura(s) que daí possa(m) desabrochar. Desse modo poderá contribuir para a formação de leitores que entendam a partilha e o cuidado enquanto aspetos fundamentais que se entrelaçam na rede de afetos que deve amparar e fortalecer as práticas de cidadania em que participam(os).

\section{Referências}

Amaral, A. L. (2012a). Como Tu. Ilustrações de Elsa Navarro. Vila do Conde: Booklândia.

Amaral, A. L. (2012b, 3 de dezembro). Ler mais, ler melhor. Como Tu, de Ana Luísa Amaral, com ilustrações de Elsa Navarro. Entrevista a Teresa Sampaio. Disponível em https://www.youtube.com/watch?v=TQ6LkhOPvfg

Amaral, A. L. (2012c, 9 de setembro). Como Tu. Programa «Bom dia Portugal». Lisboa: RTP. Disponível em

https://www.rtp.pt/noticias/cultura/como-tu-alia poesia-a-musia-para-abordar-temas-complexos-ascriancas_v585584

Cardona, M. J., Nogueira, C., Vieira, C., Uva, M. e Tavares, T. C. (2015). Guião de educação, género e cidadania: pré-escolar. Lisboa: Editorial do Ministério da Educação e Ciência.

Cruz, J., Almeida, M., Pinto, P., Constante, P., Macedo, A., Amaral, ... Ferreira, C. (2014). Contribuição da literacia emergente para o desempenho em leitura no final do $1 .^{\circ}$ CEB. Análise Psicológica, 3 (XXXII), 245257. http://dx.doi.org/1014417/ap.749

Gómez, M. N. (2013). Acerca de lecturas, lectores y mediadores: el trabajo con el libro álbum. Fundamentos en Humanidades, II (28), 115-127. Disponível http://fundamentos.unsl.edu.ar/pdf/revista-28.pdf

Lapeña Gallego, G. (2013). Intencionalidad estética y narrativa de la doble página en el álbum ilustrado. AILIJ (Anuario de Investigación en Literatura Infantil y Juvenil), 11, 81-92. Disponível em https://digitum.um.es/jspui/bitstream/10201/38277/1/ GloriaLape..3.pdf

Leal, T., Gamelas, A. M., Peixoto, C \& Cadima, J. (2014). Linguagem e literacia emergente. Propostas de intervenção em jardim de infância. In F. 1. Viana, I. Ribeiro e A. Baptista (Coord.). Ler para ser. Os caminhos antes, durante e... depois de aprender a ler (pp. 175-205). Coimbra: Almedina.

Lavanchy, A., Gajardo, A. \& Dervin, F. (2011). Interculturality at stake. In F. Dervin, A. Gajardo e A. Lavanchy (Eds.) Politics of interculturality (pp. 1-28). Newcastle upon Tyne: Cambridge Scholars.

Layne, H. \& Dervin, F. (2016). Problematizing Finland's pursuit of intercultural (kindergarten) education. Multicultural Education Review, 8 (2), 118-134.

Marques, J. F. \& Borges, M. (2012). Educação inter/multicultural no jardim de infância. Os livros infantis e as suas imagens de alteridade. Educação, Sociedade e Culturas, 36, 81-102.

Mendes, T. \& Velosa, M. (2016). Literatura para a infância no jardim de infância: contributos para o desenvolvimento da criança em idade pré-escolar. Pro.posições, 27 (2), 115-132. Disponível em http://www.scielo.br/pdf/pp/v27n2/1980-6248-pp-2702-00115.pdf

Muñoz, B. \& Anwandter, A. (2011). Manual de lectura temprana compartida: ¿por qué es importante y cómo ler com niños y niñas de 0 a 7 años? Chile: Consejo 
Nacional de la Cultura y las Artes/Fondo Nacional de Fomento del Libro y la Lectura.

Noreña, C. A. R. \& Daza, D. P. C. (2013). La lectura en la primera infancia. Grafías Disciplinares de la UCP, 20, 7-21. Disponível em http://biblioteca.ucp.edu.co/OJS/index.php/grafias/arti cle/view/1371/1299

Pereira, I. (2016). «Eu também posso ser ilustrador». Contributos do projeto curricular integrado no desenvolvimento de múltiplas linguagens no jardim de infância. In F. I. Ferreira, C. I. Anjos, A. A. Duarte, E. Fernandes, N. H. R. Franco, S. E. Santos \& T. Sarmento (Orgs.). Atas do II Seminário LusoBrasileiro de Educação de Infância. Investigação, formação docente e culturas da infância (pp.161-169. Braga: Universidade do Minho.

Ramos, A. M. (2011). Apontamentos para uma poética do álbum contemporâneo. In B.-A. R. Rechou, I. S. López \& M. N. Rodríguez (Coord.), O álbum na literatura infantil e xuvenil 2000-2010 (pp. 13-42). Vigo: Edicións Xerais de Galicia

Ramos, A. M. (2012). Como Tu. Ilustrações de Elsa Navarro para o texto de Ana Luísa Amaral. Comentário à exposição realizada na ESAD. Disponível em: http://www.esad.pt/pt/news/como-tu

Santos, M., Araújo e Sá, M. H, e Simões, A. R. (2012). Interculturality and intercultural education representations and practices of a group of educational partners. L1 - Educational Studies in Language and Literature, 12, 1-21.

Saracho, N. (2017). Research, policy, and practice in early childhood literacy. Early Child Development and Care, 187, 305-321. http://dx.doi.org/10.1080/03004430.2016.1261512

Sebastián, R. G. (2016). Manual de literatura infantil y educación literaria. Santander: Editorial de la Universidad de Cantabria.

Silva, I. L., Marques, L., Mata, L. \& Rosa, M. (2016). Orientações curriculares para a educação pré-escolar. Lisboa: Ministério da Educação: Direção-Geral da Educação.

Starkoff, V. (2010). Dançar nas nuvens. Tradução de A. M. Noronha. Matosinhos: Kalandraka.

Sotto-Mayor, G. (2016). Ilustração de livros de LIJ em Portugal na primeira década do século XXI: caracterização, tipificação e tendências. Porto: Tropelias \& Companhia.

Tabernero, R. (2013). El lector literario en los grados de maestro: deconstruir para construir. Lenguaje y Textos, 38, 47-56. Disponível em http://www.sedll.org/sites/default/files/journal/el_lect or_literario_en_los_grados_de_maestro_deconstruir_ para_construir._tabernero_r.pdf

Torres, A, Figueiredo, I. L., Cardoso, J. \& Pereira, L. T. (2016). Referencial de educação para o desenvolvimento - educação pré-escolar, ensino básico e ensino secundário. Lisboa: Ministério da Educação.

UNESCO (2006). UNESCO guidelines on intercultural education. Paris: UNESCO.

Valtin, R., Bird, V., Brooks, G., Brozo, B., Clement, C., Ehmig, S., ... Tamburlini, G. (2016). European declaration on the right to literacy. Cologne: European Literacy Policy Network.

Villalón, M. E. Z. \& Viviani, M. J. (2009). Fomento de la lectura en la primera infancia. Chile: Pontificia Universidad Católica de Chile. 